\title{
Characteristics of Actinomyces SPP. AND NocaRdia SPP. SIMULATING NEOPLASIA
}

\section{Aline Gehlen Dall Bello1, Cecília Bittencourt Severo ${ }^{2,3}$, Bruno Hochhegger ${ }^{4}$, Flavio de Mattos Oliveira ${ }^{3}$, Edson Marchiori ${ }^{5}$, Luiz Carlos Severo ${ }^{3,6}$}

\section{ABSTRACT}

Clin Biomed Res. 2015;35(2):104-109

1 Department of Molecular Microbiology, Federal University of Health Science of Porto Alegre (UFCSPA). Porto Alegre, RS, Brazil.

2 Mycology and Parasitology Department, Federal University of Health Science of Porto Alegre (UFCSPA). Porto Alegre, RS, Brazil.

3 Micology Laboratory, Hospital Santa Rita, Irmandade de Misericórdia Santa Casa de Porto Alegre (IMSCPA). Porto Alegre, RS, Brazil.

\footnotetext{
4 Radiology Department, Federal University of Health Science of Porto Alegre (UFCSPA). Porto Alegre, RS, Brazil.
}

\footnotetext{
5 Radiology Department, Federal University of Rio de Janeiro (UFRJ). Petrópolis, RS, Brazil.
}
6 Department of Internal Medicine, Federal University of Rio Grande do Sul (UFRGS). Porto Alegre, RS, Brazil.

Corresponding autor:

Aline Gehlen Dall Bello

E-mail: alinegdb@ibest.com.br; alinegb@ ufcspa.edu.br

Laboratório de Microbiologia Molecular, Universidade Federal de Ciências da Saúde de Porto Alegre Rua Annes Dias, 285. 90020-090, Porto Alegre, RS, Brasil. neoplastic diseases, mainly in lungs.

Methods: A retrospective study based on the analysis of the medical records of five cases of actinomycosis and nocardiosis, which has been primarily misdiagnosed as lung cancer according to their radiographic findings. Cases were selected from a sample of 38 patients diagnosed with actinomycosis and 29 patients diagnosed with nocardiosis at the Mycology Laboratory of Irmandade de Misericórdia Santa Casa de Porto Alegre (state of Rio Grande do Sul, Brazil) between January 1977 to December 2012. The diagnosis was established by culture and histological examination. The literature was also critically reviewed.

Results: We reported data of three cases of nocardiosis and two cases of actinomycosis that was primary diagnosed as lung cancer. The patients' mean age was 50.6 (ranged from 43-63), four were male and $80 \%(4 / 5)$ of patients were immunocompetent. In more than $50 \%$ of patients, diagnosis and also treatment of lesions required surgical intervention.

Conclusions: The complete knowledge of disease manifestations accelerates diagnosis and treatment and decreases unnecessary surgical interventions and morbidity and mortality rates, which are high in these infections.

Keywords: Actinomycosis; nocardiosis; neoplasia

Actinomyces spp. and Nocardia spp. belong to the group of bacteria in the order Actinomycetales. The main agent of actinomycosis is Actinomyces israelii'. Actinomycosis is a rare, chronic, and slowly progressive bacterial infection that induces suppurative and granulomatous inflammation ${ }^{2}$. It has been documented in all age groups, with higher incidence in middle-aged individuals and in men. It is not typically considered an opportunistic infection ${ }^{3}$. Administration of high-dose intravenous penicillin for a long period of time is the primary treatment ${ }^{2}$. Early diagnosis has better prognosis with a high likelihood of cure.

Nocardia spp. are common in the environment worldwide, and infection by these bacteria has been reported in all ages and races, being two to three times more common in men ${ }^{4}$. It occurs mainly in patients with a deficiency of local pulmonary defense or systemic immunosuppression ${ }^{5,6}$. Nocardia asteroides complex is considered the most common species associated with human disease ${ }^{1}$. Treatments for nocardisosis include surgical drainage and antimicrobial agents. Trimethoprim-sulfamethoxazole (TMP-SMX) is considered the therapy of choice, and combinations of TMP-SMX with aminoglycoside or carbapenem are recommended for 6 to 12 months for nocardial brain abscesses ${ }^{5}$.

Many infections can resemble neoplastic diseases clinically and radiologically ${ }^{7}$. These infections can cause lesions that combine chronicity, progression through anatomical barriers, and production of masses similar to those found in cancer 
patients. In the present study, we investigated and described clinical and laboratorial findings of patients with Actinomyces spp. or Nocardia spp. infections simulating lung neoplasm. We consider that better understanding of these infections improves early diagnosis and decreases misdiagnosis.

\section{METHODS}

This is a retrospective study based on the analysis of the medical record of five cases of actinomycosis and nocardiosis that have been primarily misdiagnosed as lung cancer according to their radiographic findings. Cases were selected from a sample of 38 patients diagnosed with actinomycosis and 29 patients diagnosed with nocardiosis at the Mycology Laboratory of Irmandade de Misericórdia Santa Casa de Porto Alegre (state of Rio Grande do Sul, Brazil) between January 1977 to December 2012.

The radiological criteria for inclusion in the study were the following: presence of multiple lesions with predominance of pulmonary lesions in the lower lobes or presence of a solid solitary lesion with homogeneous soft-tissue attenuation and without benign calcification or spiculated margins.

The sample was analyzed to obtain information regarding signs and symptoms, underlying disease, diagnostic evaluation, clinical and radiological features, treatment, and outcome. A microbiological diagnosis was established by histological examinations (Kinyoun, Ziehl-Neelsen, Gram-Brown-Brenn, Giemsa, and methenamine-silver stains) and culture (aerobic, anaerobic).

\section{RESULTS}

From a total sample of 38 patients diagnosed with actinomycosis and 29 with nocardiosis in a 35-year period, two cases of actinomycosis $(5 \%, 2 / 38)$ and three of nocardiosis $(10 \%, 3 / 29)$ were selected. All five cases had been primarily misdiagnosed as lung cancer. The age of the patients ranged from 43 to 63 years (median, 50 years), and four patients were male. The immune system was compromised in one patient with renal transplantation. Disseminated nocardiosis was reported in one immunocompetent patient.

All articles addressing the diagnosis of actinomycosis and nocardiosis were identified by a search on MEDLINE (National of Medicine, Bethesda, MD) database using terms such as Actinomyces, Nocardia, nocardiosis simulating neoplasia, actinomycosis simulating neoplasia, pulmonary actinomycosis, pulmonary nocardiosis, Nocardia brain abscess. This search was complemented by a manual search on Index Medicus and a cross-referencing of published articles. We included only cases of pulmonary infection simulating neoplasia that met the same criteria used to select our case series. We found 12 cases of actinomycosis and 6 cases of nocardisosis (table 1).

\section{CASE 1}

A 57-year-old male was admitted to the hospital complaining of chest pain for 2 months. On physical examination he presented with fever, cough, dyspnea, and dental caries. Chest X-ray showed signs of

Table 1: Literature review of cases of actinomycosis and nocardiosis simulating lung cancer.

\begin{tabular}{lcc}
\hline & Actinomycosis (n=12) & Nocardiosis (n=6)\# \\
\hline Age (mean) & 50 & 56 \\
Female/ male & $3 / 9$ & $1 / 5$ \\
Immunocompetent & $11(92 \%)$ & $4(67 \%)$ \\
Immunocompromised & $1(8 \%)$ & $2(33 \%)$ \\
Chest computed tomography & & $1(17 \%)$ \\
$\quad$ Pulmonary infiltrates & $2(17 \%)$ & $5(83 \%)$ \\
$\quad$ Mass/nodules & $10(83 \%)$ & - \\
Site of infection & & $5(83 \%)$ \\
$\quad$ Right upper lobe & $3(25 \%)$ & - \\
$\quad$ Right lower lobe & $3(25 \%)$ & $1(17 \%)$ \\
$\quad$ Left upper lobe & $2(17 \%)$ & - \\
$\quad$ Left lower lobe & $3(25 \%)$ & $1(17 \%)$ \\
Middle lobe & $1(8 \%)$ & $3(50 \%)$ \\
$\quad$ Treatment & & $1(17 \%)$ \\
$\quad$ Surgical & $1(8 \%)$ & $3(50 \%)$ \\
$\quad$ Antibiotics & $4(33 \%)$ &
\end{tabular}


consolidation and fibroatelectasic retraction of the left upper lobe. The patient had a presumptive diagnosis of cancer and returned three months later, when a new radiograph revealed increased lung injury with small necrotic cavities. Transbronchial needle aspiration was performed, special stain using the Gram-Brown-Brenn method was positive for filamentous bacteria, and Kinyoun and Ziehl-Neelsen stain were negative for acid-fast bacteria . Actinomyces spp. was isolated from anaerobic culture. Treatment was initiated with penicillin G (24 million UI/day/2 weeks), continued with procaine penicillin $(600,000 \mathrm{UI} / 12$ hours/2 weeks), and finished with erythromycin ( $2 \mathrm{~g} /$ day $/ 6$ months). After one-year follow-up he presented in good clinical condition.

\section{CASE 2}

A 46-year-old male, smoker, alcoholic, previously healthy, was treated for bronchopneumonia for a period of 3 months, without clinical improvement. He presented with systemic symptoms and signs of meningeal irritation and started therapy with dexamethasone $12 \mathrm{mg} /$ day. After 40 days of steroid therapy, chest $\mathrm{X}$-ray showed pulmonary nodules in the right axillary segment, suggesting malignancy. Pulmonary auscultation revealed diffuse tracheal stenosis. A transcutaneous fine needle aspiration showed chronic inflammation with mild interstitial fibrosis in the parenchyma and was negative for malignant cells. Abdominal ultrasound was normal. Brain computed tomography (CT) showed multiple nodular lesions with cortical involvement in the parietal lobes and in the posterior fossa. Open lung biopsy was performed of the middle lobe, revealing Gram-positive branched filaments. Additionally, Kinyoun stain was positive for acid-fast bacteria, and Nocardia was also isolated in culture. The patient started treatment with SMX-TMP, but he had clinical worsening and died one month after the diagnosis of nocardiosis.

\section{CASE 3}

A 44-year-old male presented with hemoptysis. This patient had a history of several hospitalizations for the same reason without a diagnosis. In addition, he complained of anorexia, asthenia, dyspnea, and left chest pain. A chest radiograph showed atelectasis of the left upper lobe and bronchial and lingular stenosis. The patient underwent left upper lobectomy. Microscopic examination of the lung tissue stained by Gram-Brown-Brenn and Kinyoun techniques revealed filamentous bacteria consistent with Nocardia spp.

\section{CASE 4}

A 43-year-old male, smoker, previously healthy, was admitted with symptoms of pneumonia (chest pain and weight loss of $12 \mathrm{~kg}$ ). He had a history of pneumonia, treated with azithromycin, a year ago. Chest CT showed multilobulated lesion with soft tissue density and calcification in the left lower lobe (figures 1 and 2). Lung biopsy stained by hematoxyline and eosine (H\&E) showed sulfur granules and Gram stain showed characteristic Gram-positive filamentous bacteria, and Actinomyces israelii grew in anaerobic culture. The treatment of choice would be penicillin

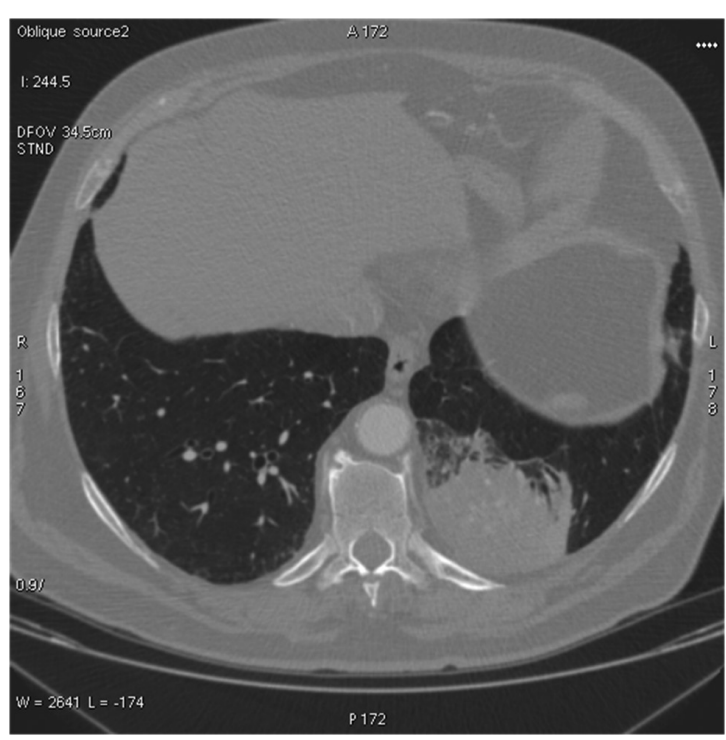

Figure 1: Computed tomography of the thorax showing a multilobulated lesion with soft tissue density and calcification in the left lower lobe.

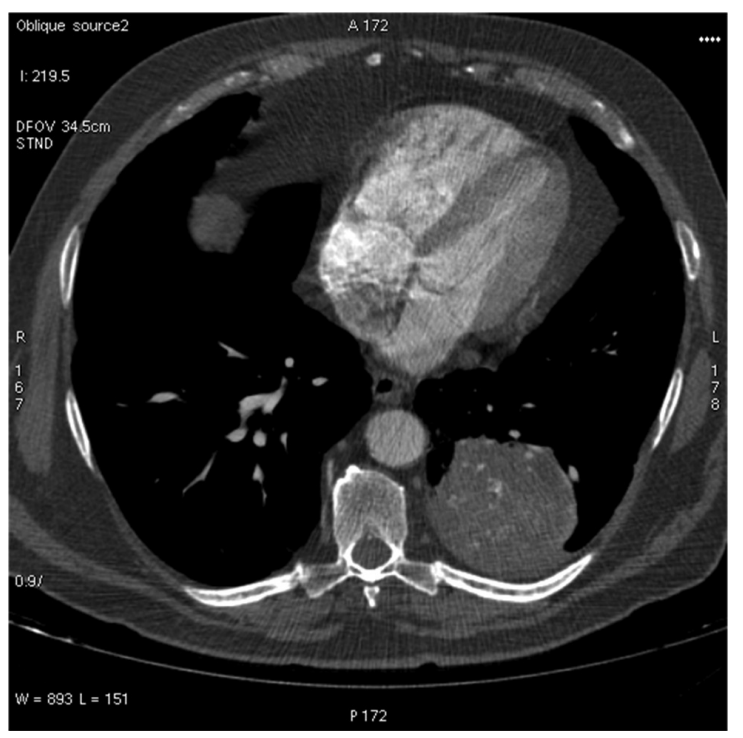

Figure 2: Mediastinal window of computed tomography. 
G in high doses (18 million to 24 million IU/day) for 2-6 weeks, then oral amoxicillin for 6-12 months ${ }^{1,2}$.

\section{CASE 5}

A 63-year-old female who had undergone renal transplantation presented with productive cough. A chest CT showed lesion in the right lower lobe, with a halo of ground-glass opacities and hilar lymphadenopathy (figure 3 and 4), suggestive of a neoplastic lesion. Laboratory analysis of lung biopsy showed Gram-positive filamentous bacteria, Kinyoun stain was positive for acid-fast bacteria, and Nocardia $\mathrm{sp}$ was also isolated in culture. SMX-TMP is currently accepted as the first-line treatment for nocardiosis.

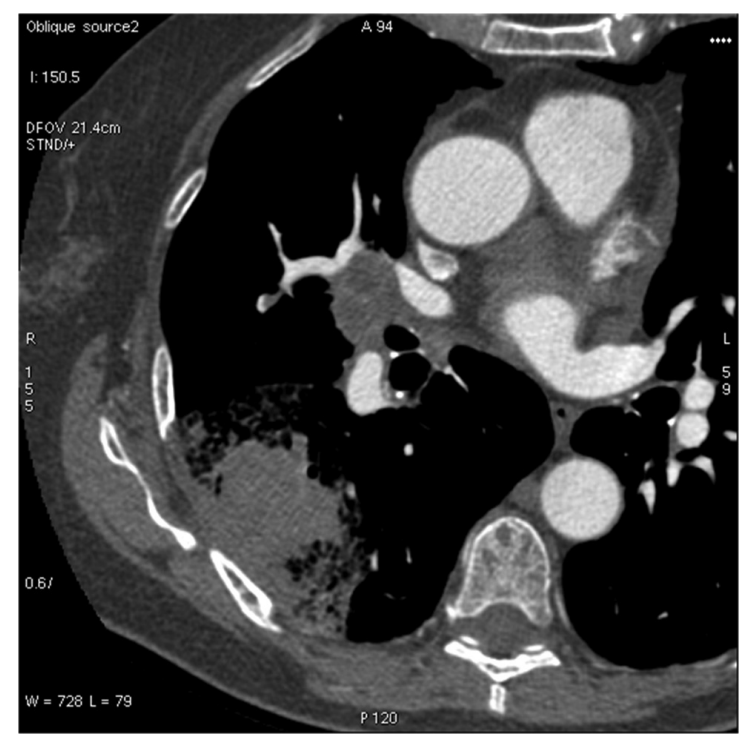

Figure 3: Computed tomography of the thorax showing a lesion in the right lower lobe, with a halo of ground-glass opacities and hilar lymphadenopathy.

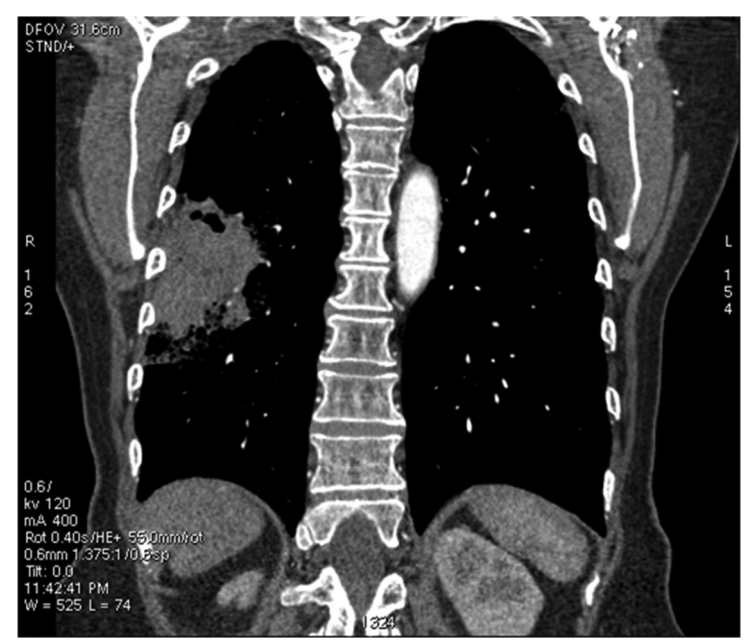

Figure 4: Reconstruction of a computed tomography (figure 3 ) in the coronal plane.
Furthermore, the antimicrobial susceptibility of Nocardia sp to meropenem, amikacin and ceftriaxone has also been reported to be high $^{4,5}$.

\section{DISCUSSION}

Actinomyces spp. bacteria are components of the oropharynx human microbiota, gastrointestinal tract, and female genital tract; they have low virulence, being unable to penetrate the intact mucosa ${ }^{4,8}$. Actinomycosis manifested clinically by combining chronicity, progression through anatomical barriers, and production of tumor-like lesions that mimics cancer ${ }^{3}$. The main clinical presentations are cervicofacial, abdominal-pelvic and thoracic ${ }^{1,9}$.

Pulmonary actinomycosis represents approximately $15 \%$ of the total burden of disease ${ }^{3}$. Thoracic involvement can be seen as a bronchopulmonary disease that produces chronic inflammation, fibrosis, and cavitation resulting in invasion and destruction of the surrounding structures ${ }^{10-12}$. Imaging tests usually reveal an area of persistent subsegmental consolidation or a mass that can cavitate ${ }^{13}$. It may invade the interlobar fissures, pleura, chest wall, soft tissue, and even bone and mediastinum ${ }^{14}$. In our review, $83 \%$ of cases have presented lesions in the form of masses/nodules, and $92 \%$ (11/12) of the cases of actinomycosis occurred in immunocompetent patients (table 1).

A case series from Korea ${ }^{2}$ found that common clinical manifestations of actinomycosis are cough, hemoptysis, and sputum; moreover, consolidation is the predominant radiological feature on CT scan and the majority cases are initially diagnosed as lung cancer. In our cases, two cases (1 and 4) showed the importance of the differential diagnosis of lung cancer diseases and that late diagnosis and inadequate treatment lead to clinical worsening ${ }^{15}$. In case 1 , the patient underwent the growth rate test, excluding neoplastic disease. This was based on the observation that benign lesions usually have doubling times of fewer than 30 days or greater than 450 days, and malignant lesions have doubling times between these values ${ }^{16}$.

Nocardia spp. are filamentous, branched, Grampositive, acid-fast resistant, aerobic bacteria that live freely in the soil, are ubiquitous in nature, and have a worldwide distribution ${ }^{17}$. The isolation of Nocardia spp. in patients should be carefully evaluated for the presence of disseminated disease, especially in immunocompromised hosts ${ }^{1}$. This condition often affects patients with leukemia, lymphoma, transplantation, AIDS, chronic lung disease (chronic obstructive pulmonary disease, asthma, sarcoidosis, and bronchiectasis) or using corticosteroids ${ }^{5,6}$. Nocardiosis occurs mainly by inhalation of bacterial 
fragments. Colonial morphology, filamentation and fragmentation are extremely variable among clinical isolates. Aerial filaments distinguish the genus Nocardia from related nocardioform gram-positive bacteria (Rhodococcus, Gordona, Tsukamurella, Actinomadura, and Corynebacterium species) and mycobacteria ${ }^{17}$.

In pulmonary nocardiosis, chest radiographs demonstrated a variety of findings, such as lumbar infiltrate, cavitation, nodules, and pleural involvement ${ }^{18}$. The most common feature found on chest CT is consolidation, usually large and often with cavitation. Some patients have single or multiple cavitary lesions that may, giving a thick wall abscess, be crucial to differentiate from cancer ${ }^{13,17}$. A retrospective study carried out in China revealed that pulmonary disease was the most common presentation of nocardiosis $(85.0 \%)$ and that the most frequent chest CT results were airspace opacities, multifocal nodules or masses ${ }^{18}$. Because of this variety of findings, sometimes nocardiosis can simulate neoplastic disease, which occurred in our cases 2, 3, 5, and one case published by our group ${ }^{19}$.

Disseminated nocardiosis is often a late-presenting and potentially life-threatening infection with a mortality rate of $7-44 \%$ in immunocompetent patients and greater than $85 \%$ in immunocompromised ${ }^{17}$. Approximately $50 \%$ of all cases of pulmonary nocardiosis will disseminate to other organs, usually the brain, through the blood stream ${ }^{1,20}$. Case 2 of our series and $83 \%$ of the cases of nocardiosis reported in literature (table 1) had brain involvement and worse prognosis. Nocardia spp. brain abscess is extremely rare ${ }^{21,22}$, accounting for about $2 \%$ of all bacterial abscesses, and the mortality rate of patients with this condition is three times higher than that of patients with other bacterial infections ${ }^{23,24}$.
The infections that simulated cancer described here occurred mostly in immunocompetent patients, and the lung was the main organ involved ${ }^{25}$. There are no secure distinguishing characteristics to differentiate infections from neoplasms. In patients with suspected Nocardia and Actinomyces infection, a definitive diagnosis usually depends on the detection of the organisms in smears or sections examined microscopically together with isolation and identification by microbiological culture. Many pathogenic Nocardia species organisms from clinical material are variably acid-fast on primary isolation, a property quickly lost in subcultured colonies. Compared to Mycobacterium species, they retain fuchsine less tenaciously, so the modified Kinyoun stain that decolorizes is best for demonstrating the variable and transient acid-fast property of Nocardia species ${ }^{26}$. Actinomyces species are blue with Giemsa stains, dark gray or black with the Grocott-Gomori methenamine-silver stain (GMS) and not acid-fast when stained by the Ziehl-Neelsen or Kinyoun method ${ }^{5}$. The importance of direct microscopic examination of stained preparations of clinical specimens in the diagnosis of Actinomyces infections cannot be overemphasized. However, this examination may provide a rapid and specific diagnosis of the patient's infection, and the information that it yields may critically influence the clinician's choice of initial antimicrobial therapy.

In summary, infections by Nocardia spp. and Actinomyces spp. may resemble neoplastic disease. The complete knowledge of disease manifestations accelerates diagnosis and treatment and decreases unnecessary surgical interventions and morbidity and mortality rates, which are high in these infections.

\section{Conflicts of interest}

The authors declare no conflicts of interest.

\section{REFERENCES}

1. Sullivan DC, Chapman SW. Bacteria that masquerade as fungi: actinomycosis/nocardia. Proc Am Thorac Soc. 2010;7(3):216-21. http:// dx.doi.org/10.1513/pats.200907077AL. PMid:20463251.

2. Kim SR, Jung LY, Oh IJ, Kim YC, Shin KC, Lee MK, et al. Pulmonary actinomycosis during the first decade of 21st century: cases of 94 patients. BMC Infec Dis. 2013;13:216.

3. Russo T. Agents of actinomycosis. In: Mandell GL, Bennett JE, Dolin $R$, editors. Principles and pratice of infectious diseases. 6nd ed. Elsevier Churchill Livingstone; 2005. p. 2924-34.
4. Yildiz O, Doganay M. Actinomycoses and Nocardia pulmonary infections. Curr Opin Pulm Med. 2006;12(3):22834. http://dx.doi.org/10.1097/01. mcp.0000219273.57933.48. PMid:16582679.

5. Brown-Elliott BA, Brown JM, Conville PS, Wallace RJ JR. Clinical and laboratory features of the Nocardia spp. based on current molecular taxonomy. Clin Microbiol Rev. 2006;19(2):259-82. http://dx.doi. org/10.1128/CMR.19.2.259-282.2006. PMid:16614249.

6. Saubolle MA, Sussland D. Nocardiosis: review of clinical and laboratory experience. J Clin Microbiol. 2003;41(10):4497501. http://dx.doi.org/10.1128/ JCM.41.10.4497-4501.2003. PMid:14532173.

7. Madhusudhan KS, Gamanagatti S, Seith A, Hari S. Pulmonary infections mimicking cancer: report of four cases. Singapore Med J. 2007;48(12):e32731. PMid: 18043829.

8. Brown JR. Human actinomycosis. A study of 181 subjects. Hum Pathol. 1973;4(3):319-30. http://dx.doi. org/10.1016/S0046-8177(73)80097-8. PMid:4756858. 
9. Rippon JW. Medical Mycology: the pathogenic fungi and the pathogenic actinomycetes. 3rd ed. Philadelphia: WB Saunders Co; 1988.

10. Andreani A, Rossi G, Giovannini M, Cappiello GF. Unexpected positron emission tomography-positive actinomyces-related mass of the bronchial stump. Can Respir J. 2012;19(2):77-9. PMid:22536574.

11. Pereira N, Cuevas $P$, Valencia $C$, Vega J, Gallegos I, Fernández JG, et al. Thoracic actinomycosis in the differential diagnosis of neoplasm: a propos of a case. Rev Chilena Infectol. 2012;29(4):4558. http://dx.doi.org/10.4067/ S0716-10182012000400017. PMid:23096550.

12. Han JY, Lee KN, Lee JK, Kim $\mathrm{YH}$, Choi SJ, Jeong YJ, et al. An overview of thoracic actinomycosis: CT features. Insights Imaging. 2013;4:245-52.

13. Hansell DM, Lynch DA, McAdams HP, Bankier AA. Infections of the lung and pleura. In: Hansell DM, Lynch DA, McAdams HP, Bankier AA, editors Imaging of disease of the chest. 5th ed. St. Louis: Mosby; 2010. p. 247-70.

14. Severo LC, Kaemmerer A, Camargo JJ, Porto NS. Actinomycotic intracavitary lung colonization. Mycopathologia. 1989;108(1):1-4. http://dx.doi.org/10.1007/BF00436776. PMid:2615797.

15. Severo LC, Dall Bello AG, Santos IS, Severo CB, Oliveira FM. Actinomicose no Rio grande do Sul: a propósito de 59 casos, atualizando actinomicose, nocardiose e rodococose. Rev Amb Hosp. 2011;47-9.

16. Hansell DM, Lynch DA, McAdans HP. 2010. Neoplasms of the lungs, airways, and pleura. In Hansell D M, Lynch, DA, McAdans HP, Bankier AA, editors. Imaging of Disease of the Chest, 5nd ed. Philadelphia: Elsevier Mosby; 2010. p. 247-70.

17. McNeil MM, Brown JM. The medically important aerobic actinomycetes: epidemiology and microbiology. Clin Microbiol Rev. 1994;7(3):357-417. PMid:7923055.

18. Yang M, Xu M, Wei W, Gao H, Zhang $\mathrm{X}$, Zhao $\mathrm{H}$, et al. Clinical findings of 40 patients with nocardiosis: a retrospective analysis in a tertiary hospital. Exp Ther Med. 2014;8(1):25-30.
19. Severo CB, Oliveira FM, Cunha

L, Cantarelli V, Severo LC.

Disseminated nocardiosis due to Nocardia farcinica: diagnosis by thyroid abscess culture. Rev Inst Med Trop Sao Paulo. 2005;47(6):3558. http://dx.doi.org/10.1590/ S0036-46652005000600009. PMid:16553327.

20. Menkü A, Kurtsoy A, Tucer B, Yildiz O, Akdemir H. Nocardia brain abscess mimicking brain tumour in immunocompetent patients: report of two cases and review of the literature. Acta Neurochir. 2004;146(4):411-4. http://dx.doi.org/10.1007/s00701-0040215-6. PMid: 15057538 .

21. Walter T, Zadeh G, Hawryluk G, Krzyzanowska MK. Nocardia brain abscess in a patient treated with everolimus for a metastatic insulinoma. J Clin Oncol. 2013;31(6):e73-5. http://dx.doi. org/10.1200/JCO.2012.42.1982. PMid:23182991.

22. Asano M, Fujimoto N, Fuchimoto Y, Ono K, Ozaki S, Kimura $F$, et al. Brain abscess mimicking lung cancer metastases; a case report. Clin Imaging. 2013;37(1):147-50. http://dx.doi. org/10.1016/j.clinimag.2012.04.020. PMid:23206622.

23. lannotti CA, Hall GS, Procop GW, Tuohy MJ, Staugaitis SM, Weil RJ. Solitary Nocardia farcinica brain abscess in an immunocompetent adult mimicking metastatic brain tumor: rapid diagnosis by pyrosequencing and successful treatment. Surg Neurol. 2009;72(1):74-9, discussion 79. http://dx.doi.org/10.1016/j. surneu.2008.02.025. PMid:18514285.

24. Yamada SM, Nakai E, Toyonaga S, Nakabayashi H, Park KC, Shimizu $\mathrm{K}$. A rapidly enlarging nocardial brain abscess mimicking malignant glioma J Nippon Med Sch. 2005;72(5):308-11. http://dx.doi.org/10.1272/jnms.72.308. PMid:16247233.

25. Dall Bello AG, Severo CB, Hochhegger B, Oliveira FM, Severo LC. Infecções que mimetizam câncer: avaliação retrospectiva e prospectiva de micoses e actinomicetoses. Rev Patol Trop. 2013;42:395-401.

26. Lerner PI. Nocardiosis. Clin Infect Dis. 1996;22(6):891-905. http:// dx.doi.org/10.1093/clinids/22.6.891. PMid:8783685.
27. Ariel I, Breuer R, Kamal NS, BenDov I, Mogel P, Rosenmann E. Endobronchial actinomycosis simulating bronchogenic carcinoma. Diagnosis by bronchial biopsy. Chest. 1991;99(2):493-5. http:// dx.doi.org/10.1378/chest.99.2.493. PMid:1989815

28. Boudaya MS, Smadhi H, Marghli A, Mouna $\mathrm{M}$, Charmiti $\mathrm{F}$, Ismail $\mathrm{O}$, et al. Surgery in thoracic actinomycosis. Asian Cardiovasc Thorac Ann. 2012;20(3):314-9. http://dx.doi. org/10.1177/0218492312439310. PMid:22718721.

29. Takanami I, Takeuchi K, Naruke M. Association of esophageal achalasia and pulmonary actinomycosis infection simulating bronchial neoplasm. J Thorac Cardiovasc Surg. 1999;118(1):199-200. http://dx.doi. org/10.1016/S0022-5223(99)70163-7. PMid:10384207.

30. Teixeira AN, Alves CL, Martins Filho EP, Mendes EM, Nunes JT. Actinomicose pulmonar simulando tumor de Tobias-Pancoast. Rev Soc Bras Med Trop. 2011;44(2):2602. http://dx.doi.org/10.1590/ S0037-86822011000200028. PMid:21552749.

31. Nenoff $P$, Kellermann S, Borte G, Horn LC, Pönisch W, Winkler $\mathrm{J}$, et al. Pulmonary nocardiosis with cutaneous involvement mimicking a metastasizing lung carcinoma in a patient with chronic myelogenous leukaemia. Eur J Dermatol. 2000;10(1):47-51. PMid:10694299.

32. Cianfoni A, Calandrelli R, De Bonis P, Pompucci A, Lauriola L, Colosimo C. Nocardia brain abscess mimicking high-grade necrotic tumor on perfusion MRI. $J$ Clin Neurosci. 2010;17(8):1080-2. http://dx.doi. org/10.1016/j.jocn.2009.10.039. PMid:20488710.

33. Chowdry RP, Bhimani C, Delgado MA, Lee DJ, Dayamani P, Sica GL, et al. Unusual suspects: pulmonary opportunistic infections masquerading as tumor metastasis in a patient with adrenocorticotropic hormoneproducing pancreatic neuroendocrine cancer. Ther Adv Med Oncol. 2012;4(6):295-300. http://dx.doi. org/10.1177/1758834012456415. PMid:23118805. 